Research Article

\title{
Psychiatric co morbidities in Patients with Tension Type Headache
}

\author{
Pranjali Bansal', $\underline{\text { RC jiloha }}{ }^{2}$
}

${ }^{1}$ Senior Resident, ${ }^{2} \mathrm{Head}$ of Department, Department of Psychiatry, Jamia Hamdard Medical College and Research Institute, Jamia Nagar, New Delhi, India.

DOI: https://doi.org/10.24321/2581.5822.202004

\section{I $\quad \mathbf{N} \quad \mathbf{F} \quad \mathbf{O}$}

\section{Corresponding Author:}

Pranjali Bansal, Department of Psychiatry, Jamia Hamdard Medical College and Research Institute, Jamia Nagar, New Delhi, India.

E-mail Id:

pranjali.bansal@gmail.com

Orcid Id:

https://orcid.org/0000-0002-2995-1446

How to cite this article:

Bansal P, Jiloha RC. Psychiatric Comorbidities in Patients with Tension Type Headache. J Adv Res Psychol Psychother 2020; 3(1): 19-23.

Date of Submission: 2020-01-24

Date of Acceptance: 2020-03-20

\section{$\begin{array}{llllllll}\mathbf{A} & \mathbf{B} & \mathbf{S} & \mathbf{T} & \mathbf{R} & \mathbf{A} & \mathbf{C} & \mathbf{T}\end{array}$}

Background: Contemporary literature focuses on Tension type headache as highly prevalent and debilitating which can lead to various psychiatric co morbidities.

Aim: 1)To assess the prevalence of tension type headache(both chronic and episodic). 2)To assess the psychiatric comorbidites. 3)Association between types of headache and severity of depression, severity of anxiety and severity of somatic complaints.

Materials and Method: Two hundred eighteen patients were assessed and classified according to international headache society classification (IHS). Depression, anxiety and physical somatic complaints were assessed by using Hamilton rating scales for depression anxiety and Patient Health Questionnaire Physical Symptoms (PHQ-15). The data was analyzed using the statistical software SPSS version 20.

Result: Our study showed mean age of participants with headache to be 33 years, $76 \%$ are females and $3 / 4^{\text {th }}$ of the samples are married hailing from lower socioeconomic status. Around half of the participants are housewives and $21 \%$ are employed and $12 \%$ are students. Mild levels of anxiety and physical somatic symptoms were exhibited by patients with both episodic and chronic tension type headache.

Conclusion: In this study we found that anxiety and physical somatic symptoms are co-morbid with tension type headache as compared to depression and slightly higher prevalence in female participants who suffered from episodic headaches and male participants were diagnosed with chronic tension type headache.

Keywords: Tension Type Headache (Episodic and Chronic), Depression, Anxiety, Physical Somatic Symptoms

\section{Introduction}

Tension Type Headache (TTH) is the most prevalent type of headache across all groups worldwide. TTH is disabling and associated with both psychiatric and medical co morbidities, impacting the quality of life. The disease burden is higher in those with chronic TTH (at least 10 previous episodes, $>15$ /month lasting for 30 minutes to 7 days) as compared to episodic TTH (<15days/month) form. ${ }^{1}$ 
TTH is associated with notable impairments in daily functioning and with reduction in work efficiency. It is one of the most common primary headaches with life time prevalence of $78 \%$ and global prevalence of $38 \%$, where in the prevalence is slightly higher in females with an average range of onset between 30-39 years of age. More commonly seen in Europe and in Asia. ${ }^{2}$

Higher rates of psychiatric disorders are also observed in patients with Tension type headache especially higher with chronic TTH. Patients suffering from headaches usually complaint of numerous accompanying symptoms both somatic and behavioural, which may partially relate to depression or anxiety. ${ }^{3}$ It is studied that chronic daily headache and depression share a common pathophysiology and it seems to be bidirectional. Most commonly seen co morbidities seen are generalised anxiety, panic attacks followed by mood disorder and increased suicidal ideation especially in middle aged females.

In general, persons with chronic TTH report increased levels of affective distress, also anger and hostility with more social impairment Several studies have examined the personality traits showing increased rates on neurotic triad (including hypochondriasis, hysteria and depression) who are highly conforming, preoccupied with bodily concerns, pessimistic and passive.

Studies have revealed in general, persons with TTH experience more daily stressors as compared to others. It was found that patients with recurrent TTH used maladaptive coping strategies such as avoidance, wishful thinking, catastrophizing. ${ }^{4}$

Therefore the current study with investigate the psychiatric co morbidities in patients with tension type headache.

\section{Materials and Method}

This is a cross sectional, single assessment study, conducted in department of psychiatry, Hamdard medical college and research centre, New Delhi for a period of one year. Samples were obtained from the patients who came for psychiatric evaluation in the outpatient department and who were referred for psychiatric consultation from medicine department. A total of 218 patients were assessed and diagnosed with episodic and chronic headache according to International headache society classification and ethical approval was obtained.

\section{Inclusion Criteria}

- Males and females between 18 and 65 years of age.

- Individuals who were willing to give consent for the study.

\section{Exclusion Criteria}

- Patients who were not willing to give the consent for the study.
- $\quad$ Patients with other neurological conditions.

- Patients already taking psychiatric treatment.

All patients who fulfil the inclusion criteria were explained about the purpose of the study and a written informed consent were obtained. Patients demographic data was collected through a semi structured proforma. The patients were evaluated by a trained psychiatrist and the clinical picture was assessed. They were diagnosed with tension type headache under International Headache Society classification (IHS). The patients were assessed for mild to severe depression and anxiety according to the scoring of Hamilton depression rating scale, Hamilton anxiety rating scale. The somatic and physical symptoms were assessed using Patient Health Questionnaire Physical Symptoms (PHQ-15). The data was analyzed by using 'descriptive' and 'inferential' statistics like Chi square test. The data was analyzed using the statistical software SPSS version 20.

\section{Result}

Table I.Socio demographic profile of patients

\begin{tabular}{|c|c|}
\hline $\begin{array}{c}\text { Socio Demographic } \\
\text { Variables }\end{array}$ & $\begin{array}{c}n=218 \\
n=\text { number of patients } \\
\text { frequency }(\%) / \text { Mean } \pm S D\end{array}$ \\
\hline Age & $33.54 \pm 11.47$ \\
\hline \multicolumn{2}{|l|}{ Sex } \\
\hline Male & 51 (23.4\%) \\
\hline Female & $167(76.6 \%)$ \\
\hline \multicolumn{2}{|l|}{ Religion } \\
\hline Hindu & 86 (39.4\%) \\
\hline Muslim & $130(59.6 \%)$ \\
\hline Christian & $2(0.9 \%)$ \\
\hline Others & 0 \\
\hline \multicolumn{2}{|l|}{ Marital status } \\
\hline Single & 34 (15.6\%) \\
\hline Married & $175(80.3 \%)$ \\
\hline Divorced/Seperated & $9(4.1 \%)$ \\
\hline \multicolumn{2}{|l|}{ Occupation } \\
\hline Employed & 47 (21.6\%) \\
\hline Unemployed & 15 (6.9\%) \\
\hline Student & $28(12.8 \%)$ \\
\hline Housewife & 128 (58.7\%) \\
\hline \multicolumn{2}{|l|}{$\begin{array}{c}\text { Socioeconomic } \\
\text { status }\end{array}$} \\
\hline Upper & $7(3.2 \%)$ \\
\hline Middle & $62(28.4 \%)$ \\
\hline Lower & 149 (68.3\%) \\
\hline
\end{tabular}


Table 2.Prevalence of tension type headache

\begin{tabular}{|c|c|}
\hline $\begin{array}{c}\text { Types of Tension Type } \\
\text { Headache }\end{array}$ & $\begin{array}{c}\mathbf{n}=\mathbf{2 1 8} \\
\mathbf{n}=\text { number of patients } \\
\text { frequency (\%) }\end{array}$ \\
\hline Episodic & $126(57.8 \%)$ \\
\hline Males & $29(56.8 \%)$ \\
\hline Females & $97(58 \%)$ \\
\hline Chronic & $92(42.2 \%)$ \\
\hline Males & $22(43.1 \%)$ \\
\hline Females & $70(41.9 \%)$ \\
\hline
\end{tabular}

Table 3.Assessment of severity of depression

\begin{tabular}{|c|c|}
\hline $\begin{array}{c}\text { Total Score and } \\
\text { Severity }\end{array}$ & $\begin{array}{c}\mathbf{n = 2 1 8} \\
\mathbf{n = n u m b e r} \text { of patients } \\
\text { frequency (\%)/ Mean } \pm \text { SD }\end{array}$ \\
\hline HAMD Scale & $7.0 \pm 5.02$ \\
\hline Sub clinical & $136(62.4 \%)$ \\
\hline Mild & $57(26.1 \%)$ \\
\hline Moderate & $22(10.1 \%)$ \\
\hline Severe & $3(1.4 \%)$ \\
\hline
\end{tabular}

Table 3(I).Assessment of severity of anxiety

\begin{tabular}{|c|c|}
\hline $\begin{array}{c}\text { Total Score and } \\
\text { Severity }\end{array}$ & $\begin{array}{c}\mathrm{n}=\mathbf{2 1 8} \\
\mathrm{n}=\text { number of patients } \\
\text { frequency (\%)/ Mean } \pm \text { SD }\end{array}$ \\
\hline HAMA Scale & $9.02 \pm 6.45$ \\
\hline Mild & $198(90.8 \%)$ \\
\hline Moderate & $20(9.2 \%)$ \\
\hline
\end{tabular}

Table 3(2).Assessment of severity of physical somatic symptoms

\begin{tabular}{|c|c|}
\hline $\begin{array}{c}\text { Total Score and } \\
\text { Severity }\end{array}$ & $\begin{array}{c}\mathrm{n}=\mathbf{2 1 8} \\
\mathbf{n = n u m b e r} \text { of patients } \\
\text { frequency (\%)/ Mean } \pm \text { SD }\end{array}$ \\
\hline PHQ Scale & $4.26 \pm 3.77$ \\
\hline Minimal & $130(59.6 \%)$ \\
\hline Low & $59(27.1 \%)$ \\
\hline Medium & $26(11.9 \%)$ \\
\hline High & $3(1.4 \%)$ \\
\hline
\end{tabular}

Table 1, depicts the Socio-demographic variables of patients. As shown the mean age of the current study participants is 33 years (Mean \pm SD: $33.54 \pm 11.47$ ). Majority of our study samples are females (76\%), while males contribute $23 \%$. Nearly $3 / 4^{\text {th }}$ of our study participants are married $(80.3 \%)$ and about $15.6 \%$ are single. More than half of our participants hail from lower middle (68\%) and $28 \%$ from middle economic status and $3 \%$ from upper. Nearly half of the patients ( $58 \%$ ) are housewives, $21 \%$ are employed, 12 $\%$ are students pursuing their studies and only $7 \%$ patients are unemployed. More than half of the participants belong to muslim religion, $39 \%$ are hindus.

Table 2, depicts the prevalence of tension type headache both episodic and chronic in males and females. As shown more than half of our participants were diagnosed with episodic tension type headache $(57.8 \%)$ out of which $58 \%$ were females and $57 \%$ were male participants. About $42 \%$ were diagnosed with chronic tension type headache out of which $43 \%$ were males and $42 \%$ were female participants.

Table 4.Association between type of headache and severity of depression

\begin{tabular}{|c|c|c|c|c|c|c|}
\hline \multirow{2}{*}{$\begin{array}{c}\text { Type of tension type } \\
\text { headache }\end{array}$} & \multicolumn{4}{|c|}{ Distribution } & \multirow{2}{*}{$\begin{array}{l}\text { Chi square } \\
\text { value }\end{array}$} & \multirow{2}{*}{ p-value } \\
\hline & Sub-clinical & mild & moderate & severe & & \\
\hline Episodic & 89 & 27 & 10 & 0 & 11.2 & .010 \\
\hline Chronic & 47 & 30 & 12 & 3 & 11.2 & .010 \\
\hline
\end{tabular}

*association is significant at $p$-value $<0.05$

**association is significant at $p$-value $<0.005$

$* * *$ association is significant at $\mathrm{p}$-value $<0.001$

Table 4(I).Association between type of headache and severity of anxiety

\begin{tabular}{|c|c|c|c|c|}
\hline \multirow{2}{*}{ Type of tension type headache } & \multicolumn{2}{|c|}{ Distribution } & \multirow{2}{*}{ Chi square value } & \multirow{2}{*}{ p-value } \\
\cline { 2 - 5 } & mild & moderate & 2.86 & .091 \\
\hline Episodic & 118 & 8 & 2.86 & .091 \\
\hline Chronic & 80 & 12 & & \\
\hline
\end{tabular}

*association is significant at $\mathrm{p}$-value $<0.05$

$* *$ association is significant at $p$-value $<0.005$

$* * *$ association is significant at $p$-value $<0.001$ 
Table 4(2).Association between type of headache and physical somatic symptoms

\begin{tabular}{|c|c|c|c|c|c|c|}
\hline \multirow{2}{*}{$\begin{array}{c}\text { Type of tension type } \\
\text { headache }\end{array}$} & \multicolumn{4}{|c|}{ Distribution } & \multirow{2}{*}{ Chi square value } & \multirow{2}{*}{ p-value } \\
\hline & minimal & low & medium & high & & \\
\hline Episodic & 84 & 30 & 11 & 1 & 6.93 & .07 \\
\hline Chronic & 46 & 29 & 15 & 2 & 6.93 & .07 \\
\hline
\end{tabular}

*association is significant at $\mathrm{p}$-value $<0.05$

$* *$ association is significant at p-value $<0.005$

$* * *$ association is significant at $\mathrm{p}$-value $<0.001$

Table 3-3.2 depicts the total score and severity of depression, anxiety and physical somatic symptoms. As shown mean score for depression is 7, suggesting sub clinical depression and found that more than half of the participants in the study exhibit symptoms of depression mild in severity. Mean score for anxiety was 9 , suggesting mild anxiety and physical somatic symptoms questionnaire depicts a mean score of 4 , suggesting of minimal complaints, exhibiting almost $59 \%$ of participants falling under the category, while $27 \%$ exhibit low levels of physical somatic symptoms. ${ }^{5}$

Table 4-4.2 In our study chi square test was used to compare the statistical association between type of headache and depression, anxiety and somatic complaints. The results have no significant association between them.

\section{Discussion}

While more studies have explored the impact of migraine, the disability attributable to TTH is larger worldwide than that due to migraine. TTH has a greater socioeconomic impact due to its higher prevalence. Patients with TTH, account for a greater total loss of workdays per year, psychological stress and a higher percentage of decreased social and occupational and work effectiveness. The disease burden of TTH is higher in those with Chronic TTH compared to Episodic TTH, However ETTH can also cause little disability, which can significantly impact quality of life.

In our study majority of participants are housewives (58\%), it may be due to various domestic problems such as inharmonious relations with the in-laws, invalidating husband, increased arguments with the husband which results in incompatibility, poorer communication between each other and increasingly destructive conflicts (such as avoiding discussion, fleeing the home, no respect for personal space) which provides a situation where women feel that they have nowhere to vent out their pent up emotions. $21 \%$ are employed, the nature of their work had not yield them enough money to cover the expenses to run their families. In addition they would also have significant pressure from their employers, discordance with the boss or difficulty in coping with the work environment, resulting in a hostile work environment, therefore were also insecure about their jobs leading to significant stress. ${ }^{6}$
In general, persons with CTTH have been reported increased levels of affective distress, such as depression, anxiety, and anger, also report more headache-related disability. Greater depressive symptomatology in TTH patients is particularly common in women, older persons, and those with more extensive headache histories. However, depression is also clinically related to psychological states such as anger and hostility, constructs that have been examined in several TTH studies. Persons with TTH experienced more stressful events, particularly more daily stressors, than did nonheadache controls and as the number of stressors increase there is a disproportionately greater levels of stress than might be reported by non-TTH persons. Patients use maladaptive coping strategies, such as catastrophizing, avoidance, withdrawal, and more often than non-headache controls $^{(6)}$.

For mostly there are various events that occur in people's life that might be stressful in presence of these stressors they are not able cope and adjust to the environment. Depressive and anxiety symptoms are more severe or frequent in headache sufferers than in the general population according to many studies. Chronic headaches lead to decreased quality of life, but so does episodic headaches. In our study it was found that females have more episodic headaches and males have chronic type headaches. Men and women differ in their roles, responsibilities and these socially constructed differences interact with biological differences to contribute to these ddistinctions. Males have more responsibilities to support their family, traditionally adopting the role of primary breadwinner, which contributes to their stress levels forcing them to take more stress. Women on the other hand have multiple responsibilities and role to play. Sometimes its difficult to vent out the stress related to their family especially living in the joint family.The societal norms and stigma attached earlier about women being a widower or who has had a divorced has decreased, women empower in terms of their knowledge and education and are at par to men in the recent years, this has given them a sense of independence, therefore being separated or taking divorce are increasing which increases the psychological stress.

Somatic symptoms are also with people with headaches, especially associated with anxiety or depression. According 
to various studies done in past shows that people suffering from headaches $>2$ days/ week have more somatic symptoms as compared to other people. Patients with chronic tension type headache had more significantly complained of stomach pain, difficulty in falling asleep, dizziness and indigestion and musculoskeletal complaints (8). Psychological distress is well known to be associated with increased physical symptoms, which represents a somatic expression of psychological distress.

\section{Consent}

It was taken from the patient and the attenders.

\section{Ethical Clearance}

It was taken from of Hamdard Medical College and research institute, block D, hamdard nagar, New Delhi 110062.

\section{Source of Funding: Self-funded}

\section{Conflict of Interest: None}

\section{References}

1. Heckman BD, Holroyd KA. Tension-type Headache and Psychiatric Comorbidity. Current Pain and Headache Reports 2006; 10(6): 439-447. [PubMed/ Google Scholar].

2. Crystal SC, Robbins MS. Epidemiology of Tension-type Headache. Current Pain Headache Reports 2010; 14: 449-445. Available from: https://link.springer.com/ article/10.1007\%2Fs11916-010-0146-2 [PubMed/ Google Scholar].

3. Mongini F, Rota E, Deregibus A, Ferrero L, Migliaretti $G$ et al. Accompanying symptoms and psychiatric comorbidity in migraine and tension-type headache patients. Journal of Psychosomatic Research 2006; 61(4): 447-451. Available from: https:// www.sciencedirect.com/science/article/abs/pii/ S0022399906001322?via\%3Dihub [PubMed/ Google Scholar].

4. Lampl C, Thomas H, Tassorelli C, Katsarava Z, Laínez $\mathrm{JM}$, Lantéri-Minet $\mathrm{M}$ et al. Headache, depression and anxiety: associations in the eurolight project. The Journal of Headache and Pain 2016; 17: 59. Available from: https://thejournalofheadacheandpain.biomedcentral. com/articles/10.1186/s10194-016-0649-2 [PubMed/ Google Scholar].

5. Kroenke K, Spitzer RL, Williams JB. The PHQ-15: validity of a new measure for evaluating the severity of somatic symptoms. Psychosom Med 2002; 64(2): 258-266. Available from: https://journals.Iww.com/ psychosomaticmedicine/Abstract/2002/03000/The_ PHQ115_Validity_of_a_New_Measure_for.8.aspx [PubMed/ Google Scholar].

6. Andrasik F, Blanchard EB, Arena JG, Teders SJ, Teevan RC, Rodichok LD. Psychological functioning in headache sufferers. Psychosom Med 1982; 44: 171-182. Available from: https://psycnet.apa.org/record/1982-30668-001 [Google Scholar].

7. Gesztelyi G, Bereczki D. Disability is the major determinant of the severity of depressive symptoms in primary headaches but not in low back pain. Cephalalgia 2005; 25(8): 598-604. Available from: https://journals.sagepub.com/doi/full/10.1111/ j.1468-2982.2005.00937.x?url_ver=Z39.88-2003\&rfr_ id=ori:rid:crossref.org\&rfr_dat=cr_pub\%20\%20 Opubmed [PubMed/ Google Scholar].

8. Radat F, Swendsen J. Psychiatric Comorbidity in Migraine: A Review. Cephalalgia 2004; 25: 165178. Available from: https://journals.sagepub.com/ doi/10.1111/j.1468-2982.2004.00839.x [Google Scholar]. 